Title:

Author:

Affiliation:

Bankwest Curtin Economics Centre

Curtin Business School

Curtin University

GPO Box U1987

Perth WA 6845

Australia

Email: astghik.mavisakalyan@curtin.edu.au

Phone: +61 892664412 


\title{
Gender in Language and Gender in Employment
}

\begin{abstract}
Women lag behind men in many domains. Feminist scholars have proposed that sex-based grammatical systems in languages reinforce traditional conceptions of gender roles, which in turn contribute to disadvantaging women. This article evaluates the empirical plausibility of this claim in the context of women's labour market outcomes. Based on a sample of over 100 countries, the analysis shows that places where the majority language is gender-intensive have lower participation of women in the labour force. Individual-level estimates further underscore this finding and indicate a higher prevalence of gender-discriminatory attitudes among speakers of gender-intensive languages.
\end{abstract}

Keywords: gender gaps, employment, gender role attitudes, culture, language gender systems 


\section{Introduction}

In spite of improvements based on economic development, women still lag behind men in their degree of labour market participation (e.g. UNDP 2010). The persistence of traditional views of gender roles has been a significant countervailing force for progress in important dimensions of women's empowerment (Akerlof and Kranton 2010; Duflo 2005). In particular, beliefs about the appropriate role of women in society affect women's labour market status (e.g. Fortin 2005). That culture matters has also been demonstrated for the case of second-generation immigrant women, by linking their fertility and labour market outcomes to those of women in their countries of ancestry, assuming that both share the same cultural background (e.g. Fernández and Fogli 2009). These approaches explain the differences in outcomes by differences in self-reported cultural beliefs or ancestral cultures, as proxied by the home country outcomes of women. What remains largely unexplained, however, is why we find differences in cultural gender biases to begin with.

As Fernández (2008: p.10) notes, 'the rigorous study of culture and economics is in its infancy' and the question of how cultures propagate and change has yet to be fully understood. A recent article by Alesina et al. (2013) makes a first attempt to account for the origins of gender roles by tracing them back to traditional agricultural practices. The authors show that societies which traditionally practiced plough agriculture have lower female labour force participation and a higher prevalence of attitudes favouring gender inequality today. The present article aims to advance this line of research by investigating the role of language gender systems as a possible source for the persistence of gender-biased cultures, and thereby ultimately as an explanation for gender disparities in labour market outcomes. 
It is estimated that there are nearly 7,000 languages in the world today (Boroditsky 2011). One of the many ways in which these languages differ is in their gender systems. A language possesses a gender system if it has classes of nouns which require specific inflectional agreement with other elements in the sentence (e.g. Corbett 1991). In some languages, gender is evident in almost every phrase, while in other languages it is entirely absent (Corbett 2008a). Finnish is an example of a language without a gender system. In English, pronouns in the third person are the only evidence for gender ${ }^{\mathrm{i}}$, while in Hebrew this is also reflected in other forms of agreement (e.g. nouns). As a result, there is varying reference to gender in the use of these languages, a fact which has attracted a great deal of feminist concern.

There is a longstanding view among feminist scholars that sexism exists in languages, which promotes gender inequalities (e.g. MacKinnon 1989; Spender 1985). In particular, 'sex-marking' in languages has been a subject of feminist criticism (see Saul (2010) for a general overview of feminist critical scholarship on gendered languages). One example of this is the use of singular personal pronouns in English which is impossible without knowing the sex of the person one is discussing. In her seminal work 'The politics of reality: Essays in feminist theory', philosopher Marilyn Frye writes: 'If I am writing a book review, the use of personal pronouns to refer to the author creates the need to know whether that person's reproductive cells are the sort which produce ova or the sort which produce sperm' (Frye 1983: p. 22). According to Frye (1983), this tendency to make sex relevant where it need not be is a key feature of sexism. Furthermore, with sex-marking goes a belief to the effect that there are important differences between men and women - a key factor in helping perpetuate male dominance (Frye 1983). This view receives general support from an influential line of thought in the humanities, suggesting that languages significantly 
shape our representation of the world (e.g. von Humboldt 1836 (translated in: von Humboldt 1999); Whorf 1957).

Even though feminist criticism of gendered languages has been voluminous and influential, not much is known about whether gender systems in languages are in fact associated with inequalities between men and women. That point notwithstanding, numerous reforms to make languages more gender-neutral have been initiated or proposed, with the hope that these reforms will lead to more genderequal outcomes. In Sweden, for example, the promotion of new gender-neutral terms and ways of communicating has recently been actively pursued not only by feminist movements, but also by the Swedish Language Council (Miles 2011). Some feminists have even proposed the introduction of a new language as a path towards gender equality (e.g. Elgin 1985). Given the costliness of such reforms, it is important to study the empirical plausibility of the underlying assumption: is it really the case that linguistic gender systems are linked with gender inequalities in outcomes? This article presents an attempt in that direction, by studying the implications of linguistic gender systems in the context of labour force participation.

We use a sample of over 100 countries to show that places with a genderintensive majority language have a lower female share in the labour force. Based on the World Values Surveys, we document a negative relationship between the genderintensity of the language spoken at home and the employment probability of women. Furthermore, the possession of a more gender-intensive language is associated with the prevalence of more discriminatory attitudes over women's equal access to jobs. Overall, these results are consistent with the claims of feminist scholars about adverse effects of gendered languages on women's outcomes. 
There is evidence from psychology for the existence of cognitive effects of linguistic gender systems: studies have shown that speakers of languages with sexbased grammatical gender are likely to attribute stereotypical masculine or feminine traits to nouns in the respective categories (Boroditsky et al. 2002). Beyond projecting gender features onto the world, speakers of gender-intensive languages also come to attain their own gender identity earlier than those from less-gendered language backgrounds (Guiora et al. 1982). However, these studies have not considered whether women's actual outcomes are affected by this dynamic.

There are only two other grammatical features which have so far been studied by economists. The linguistic practice of pronoun drop with respect to person indexing pronouns ('I', 'you', etc.) ${ }^{\text {ii }}$ has been used to instrument for cultural emphasis on autonomy versus embeddedness (Licht et al. 2007) and for family ties (Alesina and Giuliano 2007). More recently, Chen (2013) studied whether being required to speak in a grammatically distinct way about future events influences the number of futureoriented actions taken by speakers. The current article presents a further contribution to the newly emerging literature on language structures and economic behaviours.

The following section outlines our empirical approach and data. Section 3 presents the results, and Section 4 concludes.

\section{Empirical Strategy and Data}

\subsection{Measurement of Gender-Intensity of Languages}

The subject of this paper is the influence of linguistic manifestations of sex-based distinctions on economic outcomes. Grammatical gender is commonly understood as 
a system of agreement of classes of nouns with other elements in the sentence (see, for example, Corbett 1991). However, not all differences in grammatical gender track underlying differences in biological sex. Many nouns designate things which lack a biological sex yet may have masculine or feminine grammatical gender. For example, 'la lune' (the moon) in French carries feminine grammatical gender. On the other hand, not all nouns which refer to individuals with feminine biological sex receive the corresponding grammatical gender: German 'das Mädchen' (the girl) has a grammatical neutral gender, but biological feminine gender. Indeed, for less than half of the 112 languages in the World Atlas of Language Structures, is the assignment of nouns into genders on a semantic basis (Corbett 2008b).

In order to investigate whether there are inequalities based on biological sex, we have to rely on linguistic distinctions that grammaticalise the differences in biological sex. That is why we focus on languages' personal pronoun systems, where gender assignment is semantically organised (e.g. Audring 2008). Here, grammatical distinctions encode differences in the biological sex of the pronoun's referent. For example, the English pronoun 'he' can only correctly be used to refer to male individuals, while 'she' only applies to female individuals, and likewise in other languages.

Siewierska (2008) presents a categorisation of languages based on gender distinction in personal pronouns into six groups: 1. distinction in third-person and also the first- and/or the second-person pronouns; 2. distinction in third-person only, in both singular and non-singular; 3. distinction in third-person singular only; 4. distinction in first or second person but not third' 5. distinction in third-person nonsingular only; and 6. no gender distinction. I use this standard categorisation as a basis for defining the extent of gender-intensity of languages, taking two further 
observations, as established by Greenberg (1963), into account. Firstly, if a language has gender distinctions in the first person, it normally has distinction in the second or third person, or both. Secondly, gender is seen as typical of singular rather than nonsingular personal pronouns. Accordingly, I re-categorise the languages into three groups: 1. those with gender distinction in third-person and also the first- and/or the second-person singular pronouns; 2. those with gender distinction in third-person singular pronouns only; and 3. those with no gender distinction in pronouns. For ease of exposition, these will be referred to as: 1 . highly gendered; 2 . mildly gendered; and 3. gender-neutral languages. In all regressions the independent variables of interest are dummies for mildly gendered and highly gendered languages, with the genderneutral languages being the excluded category.

The World Atlas of Language Structures is the main source of data with a very small number of missing values which, where available, are filled through consultation of various linguistic sources. Table 1 presents the gender-intensity data for selected languages. For instance, Finnish has no gender distinction in its pronouns - thus its gender intensity appears as 0 in the table. English, on the other hand, is an example of a mildly gendered language, as its third-person pronouns distinguish across genders. However, English has no further distinction in the first and/or the second person. Hebrew is an example of a language with gender distinction in the third-person as well as the first- and/or the second-person pronouns, encoded as 2 in the table.

\subsection{Country Level Analysis}


Grammatical structures, and grammatical gender in particular, are stable over very long periods of time. As Östen Dahl, a linguist known for his pioneering work in the area of linguistic typology, puts it: 'Grammatical gender systems generally presuppose rather long evolutionary chains and are in this sense among the more clearly mature elements of language' (Dahl 2004: p. 112). Given this point, I utilise a cross-section of countries instead of a panel. The analysis is based on the year 2000, motivated by data availability on the key variables of interest.

The dependent variable is the female share of the labour force. This measure is based on the harmonised labour force participation estimates based on nationally representative labour force surveys and released by the World Bank (2004). According to the source, the estimates use strict data selection criteria and enhanced methods to ensure comparability across countries and avoid inconsistencies resulting from differences in data source, definition, reference period, coverage and age group. This notwithstanding, there remains scope for potential differences in the measurement of labour force participation across countries. Ross (2008) notes two further shortcomings associated with heterogeneity in the labour force measurement: firstly, some countries count foreign workers; and secondly, the measure does not distinguish between work in the agricultural and in the non-agricultural sectors. To deal with these limitations, I follow Ross (2008) in using an adjusted labour force measure which excludes foreign workers and agricultural workers. While the dependent variable in the baseline regressions is the female share of the native nonagricultural labour force, in the robustness checks section I report results with the female share of the total labour force used as a dependent variable.

Language gender dummies are defined with reference to the language spoken as 'mother tongue' by the majority population (Alesina et al. 2003). The relationship 
between the female share of the labour force and language gender dummies is examined in a regression framework, which includes a set of important controls. Following the approaches in existing studies on the subject detailed below, I attempt to include as many determinants of the female share of the labour force as possible while trying to avoid the danger of over-controlling, given that some of these variables may be endogenous to language gender dummies.

Given that the gender category is assigned to the language of the majority population, the share of the population comprising the linguistic majority is accounted for. The female share of the labour force is expected to depend on economic development, captured by the logarithm of GDP per capita and its squared term. Government size, measured as the total government share of GDP, is controlled for in order to reflect the possibility that larger governments may stimulate female labour force participation (for example, larger social spending, particularly on items such as public childcare subsidies and maternity leave cover, may foster women's labour force participation and attachment). To account for potentially differential effects of greater exposure to the world economy on men and women, openness - measured as the sum of exports and imports in GDP - is included in the list of controls.

Production structure, and in particular oil production, has been shown to affect the female share of the labour force (Ross 2008). Accordingly, oil rents per capita are accounted for. Democracies may also have more women in the labour force. The control for democracy is defined based on polity scores of 0 (least democratic) to 10 (most democratic) (Marshall and Jaggers 2009). Moreover, the regressions include a measure of country size (logarithm of population). Urban and rural areas may have differential employment patterns of women, and to reflect that the urban share of the population is also included in the list of controls. Protestant, Catholic, Muslim, 
Jewish, Hindu and Buddhist shares of populations are controlled for in order to allow for the effects of religious traditions on gender roles. To represent the effect of communist policies on female employment, a dummy for countries' communist past is included. Finally, dummy variables for developed Western countries (i.e. the OECD countries excluding Japan and Korea), Latin America, sub-Saharan Africa, East Asia, and North Africa and the Middle East are added.

The cross-country dataset, assembled from different sources, covers up to 108 countries in the year 2000. As Table 2 shows, some variables come from standard sources widely used in macro-level empirical studies, while in other cases datasets compiled by researchers based on standard sources and used in published articles are used. The table also presents summary statistics. The female share of the labour force across countries ranges from 17.21 percent (Oman) to 52.33 percent (Cambodia) with the average being around 40 percent. Around 31 and 39 percent of languages are highly and mildly gendered, respectively, with the rest being gender neutral.

The relationship between language gender systems and the female share of the labour force is tested using OLS estimations. Still, the effect that potential endogeneity might have on the results is considered. Places which are different for a variety of reasons may differ both in the gender intensity of their languages and in their female labour force participation. Firstly, controls to minimise the distorting effect of unobserved heterogeneity are included in the robustness checks. Secondly, a 2SLS estimation is carried out, using dummies for eight language families as instruments for language gender dummies. These are the language families which have more than one language represented in the sample.

What is the rationale behind the use of language families as instruments for language gender dummies? Grouping languages in the same family signifies that they 
have evolved from a common ancestor, a proto-language. The distinct features of such proto-languages have likely affected the structures of descendant languages, including the presence of sex-based gender systems. For example, the proto-IndoEuropean languages had a gender system, although it was based on animate/inanimate opposition rather than biological sex (Luraghi 2009). However, it is plausible that the presence of a gender system in those proto-languages, in spite of its different semantic core, has led to a higher propensity among descendent languages to have sex-based gender systems. Indeed, around 55 percent of the countries in our sample speak an Indo-European language and only around 12 percent of those languages are genderneutral.

The countries speaking an Indo-European language are geographically rather dispersed, covering parts of Europe, the Americas, Australia, but also the Middle East and Asia. The spread of language families can be traced to prehistoric times. For example, according to Diamond and Bellwood (2003), before 1492 A.D. the IndoEuropean language family spread eastwards from Ireland to the Indian subcontinent and western China. Inclusion of region dummies, as defined above, to a certain extent minimises the concerns over the instruments affecting the female share of the labour force through channels other than the language. In addition, an over-identification test to formally validate the exclusion restriction is carried out.

In spite of these improvements, it is difficult to interpret the results as causal effects. In particular, it is difficult to control for all the confounding variables which affect the dependent variable. Furthermore, it is possible to question the success of the proposed identification strategy in solving this problem. For example, the linguistic trees may be related to pre-historic migration movements, which may have taken place due to particular economic reasons affecting gender differences in labour force 
participation. For these reasons, I do not want to over interpret the results obtained through 2SLS estimation and prefer that the results are treated as more precisely estimated partial correlations, even when referred to as the 'impact' of linguistic gender for the sake of simplifying the exposition.

\subsection{Individual Level Analysis}

Some of the sources of endogeneity of language gender systems should be of lesser concern when individual-level labour market outcomes are being considered. This is done using the World Values Surveys, a collection of nationally representative, individual-level surveys on a variety of attitudes and preferences. The surveys also include information on standard demographic characteristics, such as gender and labour market status.

The dependent variable of main interest here is the employment status of respondents. The World Values Surveys distinguish respondents with and without paid employment. Accordingly, employment status is defined as a dummy which equals 1 if the respondent has paid employment (including those employed full-time, part-time or who are self-employed), and 0 if the respondent has no paid employment (housewives or unemployed). This measure of employment does not encompass all forms of gainful activity, since those involved in unpaid family production are likely to be subsumed under the categories of 'housewife' or 'unemployed'. The analysis excludes the retired and students, and is restricted to the population aged 18-65. Furthermore, the part-time employment status is also (?) considered as a dependent variable. It is a dummy which equals 1 if the respondent is employed part-time and 0 if the respondent is full-time or self-employed. In addition to the individual-level 
analysis of labour market participation, the World Values Surveys allow consideration of the attitudes to gender roles as an additional dependent variable. Of relevance to the issue of female employment are the respondents' views on the statement: 'When jobs are scarce, men should have more right to a job than women'. A dummy variable is defined equal to 1 for agreement, and 0 for disagreement.

Language gender dummies are defined with reference to the language spoken at home by the respondents. As a result, this article is restricted to the last three waves of Surveys (carried out in the period 1994-2007), where information about the language spoken at home was included. The correlation between the three dependent variables and language gender dummies is examined in a regression framework, which includes country dummies. Consequently, the analysis is restricted to up to 46 countries with non-missing values on key variables, where multiple languages with varying gender intensities are identified. ${ }^{\text {iv }}$ The regressions include year dummies, dummies for the size of a respondent's residential location (defined in 8 categories based on the resident population), as well as the same set of region dummies as in the country-level analysis. To further isolate the effect of language gender systems, a range of individual-level characteristics of respondents are included as controls.

While the home language is plausibly of most significance, other languages spoken may matter as well. In particular, recent studies in social psychology have demonstrated that a particular subject's attitudes may vary depending on the languages in which those attitudes are elicited (Danziger and Ward 2010; Ogunnaike et al. 2010). The World Values Surveys identifies the language in which the interview was conducted. Accordingly, a dummy that equals 1 if the interview is conducted in the language used at home by the respondent is included in this analysis. Another dummy included equals 1 if the interview language is of lower gender intensity than 
the language spoken at home by the respondent.

Dummies for Protestant, Catholic, Muslim, Jewish, Hindu, Buddhist and other religious denominations are included. Those without religious denomination are the excluded category. Furthermore, following the literature on the effect of religiosity on economic outcomes (Barro and McCleary 2003), I control for common aspects of religiosity by including measures of the extent of religious observance (captured in three dummies to indicate frequent (more than once a week), weekly and monthly attendance at religious services with occasional or no attendance at religious services being the excluded category) and the strength of religious beliefs (measured as a dummy for those self-reporting as being religious).

The regressions control for standard demographic characteristics, including age, marital status, number of children, race, health, and education level. Age and number of children are measured as continuous variables. Marital status is captured through dummies for married and divorced respondents (excluded category: single/never married). Race is captured through a dummy for 'white' race (excluded category: other races). Health is captured through dummies for good and poor health (excluded category: fair health). Education is captured through dummies for inadequate (no formal education or incomplete primary school), lower (completed primary school or incomplete secondary school) and middle (completed secondary school or university-preparatory type secondary education) education levels (excluded category: university-level education). Income dummies, based on the scales identified in the Surveys (in 10 steps), are also included.

\section{Results}


3.1.1. Baseline results. Column (1) of Table 3 presents the estimates of language gender dummies on the female share of the labour force on the full sample of countries. The coefficients on language gender dummies are statistically significant. They are also economically meaningful. In countries with highly gendered languages the female share of the labour force is 4.4 percentage points lower compared to the countries with gender-neutral majority languages. In countries with mildly gendered languages it is 2.3 percentage points lower.

Estimated coefficients for control variables are generally as expected. The results indicate a positive association between the female share of the labour force and the share of the largest linguistic group in the population, which can be viewed as a measure of linguistic homogeneity. This is broadly consistent with observations on positive economic outcomes in places with homogenous populations (e.g. Easterly and Levine 1997), and is similar to the finding of a negative effect of ethnic fractionalisation on female labour force participation reported in Feldmann (2007). Ross (2008) argues that oil production discourages women from entering the labour force. Consistent with Ross' point, the coefficient on oil rents per capita is negative, however very small in size. The argument that religions hold gender values detrimental to female labour force participation has received support in some studies (e.g. Heineck 2004) but not in others (e.g. Ross 2008). Accordingly, I find that places with a larger Catholic share of population have a lower female share of the labour force, while the Jewish share of population is positively associated with the female share of the labour force. Finally, the coefficient on the communist dummy is positive and significant, reflecting the lasting influence of communist policies dominated by 
labour shortage, the imperative of industrialisation, and values of equality, resulting in women being absorbed into the labour force rapidly (Pollert 2003). The coefficients on the remaining controls are not significantly different from 0 .

The documented association between linguistic gender systems and the female share of the labour force may be driven by certain observations in the sample. Several changes to the sample are considered. Arabic is among the highly-gendered languages in the sample. Some of the countries with very low female shares of labour force are Arabic-speaking. However, exclusion of Arabic-speaking countries leaves the results largely unaffected (column (2) of Table 3). Column (3) of Table 3 drops countries where the majority population speaks gender-neutral languages of the Uralic family. These are Estonia, Finland and Hungary, where the female share of the labour force is approaching half. The significance of language gender dummies remains unaffected. Communist traditions have resulted in a higher labour force participation of women in countries with a communist past. The results reported in column (4) are based on a sample which excludes the former communist countries whose majority population speaks a gender-neutral language. The coefficients on language gender dummies are significant and larger in size.

To obtain the estimates in the last two columns of table 3 , I follow a more formal approach to detect potentially influential observations. According to Donald and Maddala (1993), examination of studentised residuals is the most appropriate method for identifying influential observations, even when assessing the influence of observations on individual estimated coefficients (see Donald and Maddala 1993, for details). On the basis of studentised residuals, 6 countries are identified as being potentially influential observations. When the model is re-estimated with these countries omitted, the coefficients preserve their significance (column (5)). Donald 
and Maddala (1993) further recommend the use of leverage in conjunction with studentised residuals in order to detect outliers. Cook's distance is an overall measure of influence which combines information on the residual and leverage into a single statistic. It is applied here, resulting in 14 countries identified as outliers and dropped from the sample. The significance of the results reported in column (6) remains robust to this change in the sample. However, the magnitude of the effect of language gender dummies is smaller.

3.1.2. Robustness checks. In Table 4, I check the robustness of the results against alternative definitions of the variables. The dependent variable in the baseline regressions is the female share of the native non-agricultural labour force. In the first four columns of the table, I test the robustness of the results by using alternative measures of female labour force participation (World Bank 2004). In column (1), the dependent variable is the female share of the total labour force (without the adjustment to exclude the agricultural and foreign workers). In column (2), I use an alternative approach to measuring the gender disparities in labour force participation by exploiting the ratio of female to male labour force participation rates (economically active shares of working-age populations) as a dependent variable. Column (3) uses the female labour force participation rate itself as a dependent variable, while in column (4) the dependent variable is the female employment rate defined as the proportion of working-age female population who are employed. The estimated coefficients on language gender dummies remain negative and statistically significant when these changes to the measurement of the dependent variable are applied. Moreover, the estimated magnitudes are larger in size, reflecting the differences in the scales of the measures used.

In the baseline model, the assignment of language gender dummies is based on 
the language spoken by the majority population. This approach may be problematic for places with more diverse populations since it does not account for social divisions and cultural differences between majority and minority populations. Furthermore, some countries with diverse populations may have official languages (including those used for instruction at schools) which may not coincide with those spoken at home by the majority of the population. In an effort to incorporate the languages spoken by different population groups into the analysis, I replace language gender dummies with continuous variables which are the total population shares speaking highly and mildly gendered languages. Data on the gender of pronouns for some of the minority languages spoken in different countries are missing in our sources. As a result, for some countries, there remains a share of a population with unknown language gender characteristics. I restrict the countries in the estimation sample to those where information is available for at least 80 percent of the population, which leaves us with a sample of 85 countries to work with: the results are broadly similar for the unrestricted sample as well as for the restricted, based on information availability for at least 90 percent of the population. The regressions additionally control for the share of the population with unknown language gender characteristics, with an insignificant estimated coefficient obtained. The results presented in column (5) of Table 4 are broadly consistent with the baseline results. Places with a larger share of the population speaking highly gendered languages have a lower female share of the labour force. The relationship between the share of the population speaking a mildly gendered language and the female share of labour force, while smaller in magnitude, is also negative. However, the estimated standard error is large, yielding the coefficient statistically insignificant.

Attributing the adverse gender outcomes to languages is challenging if there is 
an endogeneity problem. In Table 5, I include controls to mitigate the effect of unobserved heterogeneity. If linguistic structures shape cognition, other linguistic attributes beyond the gender systems could matter as well. If so, it is possible that the estimated effect of language gender systems is capturing broader cognitive differences associated with speaking different languages, which may drive the labour market behaviour. One way to test this possibility is to include an additional linguistic attribute in the model. Chen (2013) has shown that obligatory future-time reference in languages significantly affects inter-temporal preference and a set of future-oriented actions. He categorises the future-time reference of a language as 'strong' if it requires the use of the future tense when speaking about future events, and 'weak' otherwise. The estimated coefficients on language gender dummies largely preserve their size and significance when this measure is included in the regressions (column (1) of Table 5). ${ }^{\mathrm{v}}$ The coefficient on future time-reference dummy is insignificant.

An additional source of concern in interpreting the results is the varying degree of prevalence of language gender systems in different parts of the world. For example, many of the countries where highly gendered languages are spoken are situated close to the southern Mediterranean shore. As a result, the effect of certain correlated spatial factors may be attributed to language gender systems. To address this concern, distance from the equator, measured as the absolute value of latitude in degrees divided by 90, is added as a control. As the results reported in column (2) of Table 5 demonstrate, its coefficient is positive and significant. However, its inclusion does not affect the estimated coefficients on language gender dummies.

Previous studies have considered the distance from the equator as a proxy for geography (e.g. Rodrik et al. 2004) as well as for Western European influence (Hall and Jones 1999). So I next consider direct measures to capture both dimensions. 
Climatic and location factors are added as controls for geography. The climatic factors are the share of population in tropical climate zones and the average number of frost days per unit of population; and the location factors are the share of population within $100 \mathrm{~km}$ of the coast or an ocean-navigable river and a dummy for a country's landlocked status (Gallup et al. 1999; Masters and McMillan 2001). The results are reported in column (3) of Table 5. Countries with a larger share of population close to coastal areas have a higher female share of the labour force. The coefficients on language gender dummies remain robust to inclusion of these additional controls.

Hall and Jones (1999) claim that the distance from the equator proxies for the Western European influence, since Western Europeans were more likely to settle in sparsely populated and climatically similar areas. The model is next augmented with more direct measures of Western European influence, including dummies for former British and French colonies, as well as dummies for English common law and French civil law traditions (La Porta et al. 1998). As the results demonstrate, former French colonies have a higher female share of the labour force (column (4) of Table 5). The coefficients on language gender dummies are not affected.

An important consequence of colonisation policies is the creation of different types of social and political institutions. Labour market regulations, in particular, bear considerable influence upon incentives to work. In column (5) of Table 5, I explore the extent to which the estimates of language gender systems are potentially capturing the effect of these regulations on the female share of the labour force, by adding three measures. Unemployment benefits are defined as the level of statutory entitlements in relation to average wages over two years of unemployment. This indicator captures the percentage of earnings which is replaced by benefits. Employment protection 
legislation is proxied by measures for maximum advance notice period and severance pay for no-fault individual dismissals. The data comes from the fRDB-IMF Labour Institutions Database (Aleksynska and Schindler 2011). In spite of the estimation sample being restricted to 73 countries due to missing data, the estimated coefficients on language gender dummies remain significant. Moreover, the estimated negative effect of highly gendered languages is larger in magnitude.

In spite of the robustness of the results to the inclusion of these additional controls, the possibility of unobserved differences other than language gender systems driving the female labour force participation cannot be completely ruled out. Importantly, there may be unobserved cultural elements correlated with the presence of linguistic gender systems as well as the female share of the labour force. Therefore, to consistently estimate the impact of language gender systems on the female share of the labour force, a 2SLS estimation is carried out, using dummies for eight language families as instruments. The last column of Table 5 reports the results. The coefficients on language gender dummies preserve their signs and statistical significance. Their magnitude is slightly larger than OLS estimates. The instruments are jointly highly significant in the first stage, as demonstrated by F-statistics reported in the bottom part of the table. An over-identification test to detect whether the instruments have a direct effect on the female share of the labour force is also carried out with the p-value indicating no evidence of a direct effect. Nevertheless, as discussed in the preceding section, ruling out the potential threats to exogeneity of the instruments exploited for identification is challenging, thereby limiting the scope for interpretation of these estimates as causal effects of language gender systems.

\subsection{Individual Level Estimates}


Table 6 presents the results of the individual level analysis of language gender systems and labour market outcomes. Firstly, I consider models where the dependent variable is the employment status of the respondent. Consistent with country level estimates, the estimated marginal effects of language gender dummies based on the women's sample have negative signs. Similarly, the marginal effect of speaking a highly gendered language is larger than the marginal effect of speaking a mildly gendered language. However, only the marginal effect of speaking a mildly gendered language is statistically significant. Women who speak a mildly gendered language are 11.7 percentage points less likely to be employed as compared to those who speak a gender-neutral language.

Consistent with the literature on the negative effects of religions on women's outcomes (e.g. Heineck 2004), the results show that Muslim and Hindu women are less likely to be employed as compared to women who do not belong to any religious denomination, while the probability of employment of those belonging to a religion other than the six major religions specified in the model, is higher. Similarly, attendance at religious services on at least a monthly basis is associated with a negative probability of employment. Other demographic characteristics which have a statistically significant effect on women's employment probability are age, marital status, number of children, health and education status. They have by and large the expected signs.

The feminist hypothesis about the effect of linguistic gender systems predicts a negative effect only on the employment of women, but not on the employment of men. However, linguistic gender systems may be capturing the effect of linguistic elements other than sex-based gender systems, which may have broad effects on 
cognition. If that is the case, no difference across the sexes of the effect of linguistic gender systems should be expected. The estimates of language gender dummies on men's probability of employment are positive but insignificant. This suggests that it is unlikely that our estimates of language gender systems are capturing the effect of other linguistic elements. Many of the standard demographic characteristics have explanatory power over men's employment status as well.

In a next step, I consider the part-time employment status as a dependent variable in the samples of employed women and men. According to the results, the employment of female speakers of gendered languages is more likely to be on a parttime basis. The estimated marginal effect of the mildly gendered language dummy is statistically significant:, women who speak a mildly gendered language are 8.5 percentage points more likely to be employed on a part-time basis as compared to those who speak a gender-neutral language. No statistically significant effect of language gender dummies on men's part-time employment status is found.

The World Values Surveys allow us to consider the attitudes to gender roles, in addition to employment. The dependent variable considered here reflects individuals' beliefs about whether women should have equal access to jobs, which is likely to affect the female labour force participation. The results reported in the last column of Table 6 demonstrate a positive and highly significant effect of gendered languages on the probability of having gender discriminatory attitudes in the pooled sample of women and men. Speakers of both mildly and highly gendered languages are more likely to support men's privileged rights for jobs as compared to speakers of gender-neutral languages.

As expected, women are less likely to have gender discriminatory attitudes. The gender of the interview language matters as well, and in the same direction as the 
gender of the home language. The probability of expressing gender discriminatory attitudes decreases with a decrease in gender intensity of the language in which the interview was conducted. The significance of this effect is consistent with recent studies in social psychology, which have demonstrated that the language used to elicit particular attitudes affects the content of these attitudes (Danziger and Ward 2010; Ogunnaike et al. 2010). Representatives of certain religious denominations and those actively practicing a religion are more likely to have discriminatory attitudes. Similarly, older and married people, as well as those with more children, are more likely to support women's unequal access to jobs, as are less educated people.

Linguistic gender systems could be associated with traditional gender role attitudes among women as well as among men. Violating such behavioural norms for one's gender can evoke discomfort in oneself and in others. As a result, women will work less. The reason is that women's role as workers will negatively influence their traditional self-image or identity as 'women' as well as men's traditional gender identity since the field of employment will no longer be perceived as an exclusively male domain. Interaction terms of sex and language gender dummies, when included in the regressions, are insignificant, and do not affect the coefficients on language gender dummies (results are available on request). Thus, it is reasonable to conclude that language gender systems affect women's employment because of the associated influences over gender identities of both women and men.

\section{Conclusion}

Economic development alone has proved insufficient for making comprehensive advances in women's empowerment. A deeper explanation of women's deprivation 
may therefore need to include cultural factors, as well as economic and social ones (Sen 1990). A large and influential corpus of feminist literature has emphasised the role of sex-based gender systems in languages in disadvantaging women. This article represents the first attempt to test the empirical plausibility of that claim in the context of the labour market outcomes of women.

Using a country-level dataset of 108 countries in the year 2000, I showed that places where the majority language is gender-intensive have a lower female share of the labour force. Using individual level data from up to 46 countries in the World Values Surveys, I documented an association of gender-intensive languages with women's employment probability. Furthermore, I explored a belief-based variable underlying the objective outcomes. The individual-level results suggest that speakers of gender-intensive languages are more likely to hold the view that women should not have equal access to jobs.

These results attest to the proposition that gendered languages may have an adverse effect on gender equality. Moreover, they suggest that existing gender stereotypes and gaps in labour market outcomes may not go away any time soon, even if opportunities formally become equal for women and men. The results thereby extend support for initiatives to make languages more gender-neutral on grounds of efficiency since they may actually contribute to equality in outcomes.

Admittedly, more work needs to be done in order to obtain better estimates. In particular, the possibility of linguistic gender systems picking up the effects of deeper gender-biased cultural elements is hard to rule out completely in the current exercise. Intra-language comparisons are a promising path to single out the effect of language gender systems from other confounding factors. Use of gender-neutral language has been promoted in many places. In the context of the labour market, for example, 
practices of job advertisements written explicitly to be inclusive of both sexes (e.g. through the use of '/' to include terms and parts of speech applicable to each gender) have become increasingly common. Whether similar practices have an effect on women's labour force participation is yet to be explored. Experimental work holds promise in this research area.

\section{Acknowledgements}

I am indebted to Alison Booth, Nick Evans, Tue Gørgens and Clas Weber for their helpful comments and suggestions on this article. I also thank audiences at the Australian National University Research School of Economics seminar, the 10th Australian Society of Heterodox Economists Conference and the Cooperation and Conflict in the Family Conference at the University of New South Wales for interesting discussions. The comments from three anonymous referees and the editor have led to significant improvements of the initial draft.

\section{Notes}

\footnotetext{
${ }^{\mathrm{i}}$ When the referent of the pronoun is of male biological gender, English prescribes the use of the pronoun 'he', while it requires the pronoun 'she' when the speaker is talking about someone of female biological gender.

ii Languages vary on the grammatical license to drop the pronoun. While English requires including a pronoun in a clause in most cases, Spanish licenses pronoun drop; however, information about the subject can be recovered from the verb (Licht et al. 2007).

iii The results are quantitatively identical when the population is restricted to ages 2360 instead.

iv The countries in the sample are Albania, Andorra, Australia, Bangladesh, Bosnia and Herzegovina, Bulgaria, Burkina Faso, Canada, Chile, Cyprus, Egypt, Ethiopia, France, Former Yugoslav Rep of Macedonia, Ghana, Guatemala, India, Indonesia, Iran, Iraq, Jordan, Kyrgyzstan, Mali, Mexico, Nigeria, Pakistan, Philippines, Poland,
} 
Puerto Rico, Rep of Moldova, Saudi Arabia, Serbia and Montenegro (and successor Serbia), South Africa, Spain, Sweden, Switzerland, Taiwan, Thailand, Trinidad and Tobago, United Kingdom, United States, Uruguay, Venezuela, Viet Nam, Zambia.

${ }^{v}$ The data come from Chen (2013) with a small number of missing values filled in based on various linguistic sources. 


\section{References}

Akerlof, G. A. and Kranton, R. E., 2010. Identity Economics: How our identities shape our work, wages, and well-being. Princeton: Princeton University Press.

Aleksynska, A. and Schindler, M. 2011. Labour market regulation in low-, middleand high-income countries: A new panel database. IMF Working Paper, WP/11/154.

Alesina, A., Devleeschauwer, A., Easterly, W., Kurlat, S. and Wacziarg, R. 2003. 2003. Fractionalization. Journal of Economic Growth, 8(2), 155-194.

Alesina, A. and Giuliano, P. 2007. The power of the family. IZA Discussion Paper, 2750.

Alesina, A., Giuliano, P. and Nunn, N. 2013. On the origins of gender roles: Women and the plough. The Quarterly Journal of Economics, 128(2), 469-530.

Audring, J. 2008. Gender assignment and gender agreement: Evidence from pronominal gender languages. Morphology, 18(2), 93-116.

Barro, R. G. and McCleary, R. M. 2003. Religion and economic growth across countries. American Sociological Review, 68(5), 760-781.

Barro, R. G. 2007. Religion Adherence Data: http://www.economics.harvard.edu/faculty/barro/data_sets_barro.

Boroditsky, L., 2011. How language shapes thought: The languages we speak affect our perceptions of the world. Scientific American, p. 63-65.

Boroditsky, L., Schmidt, L. A. and Phillips, W., 2002. Can quirks of grammar affect the way you think? Spanish and German speakers' ideas about the genders of objects. Unpublished manuscript. 
Chen, M. K. 2013. The effect of language on economic behavior: Evidence from savings rates, health behaviors, and retirement assets. The American Economic Review, 103(2), 690-731.

Corbett, G. G., 1991. Gender. Cambridge: Cambridge University Press.

Corbett, G. G., 2008a. Number of genders. In: Haspelmath, M., et al. eds. The World Atlas of Language Structures Online. Munich: Max Planck Digital Library: Chapter 30. http://wals.info/feature/30.

Corbett, G. G., 2008b. Systems of gender assignment. In: Haspelmath, M., et al. eds. The World Atlas of Language Structures Online. Munich: Max Planck Digital Library: Chapter 32. http://wals.info/feature/32.

Dahl, Ö., 2004. The growth and maintenance of linguistic complexity. Amsterdam/Philadelphia: John Benjamins.

Danziger, S. and Ward, R. 2010. Language changes implicit associations between ethnic groups and evaluation in bilinguals. Psychological Science, 21(6), 799800.

Diamond, J. and Bellwood, P. 2003. Farmers and their languages: The first expansions. Science, 300(5619), 597-603.

Donald, S. G. and Maddala, G. S., 1993. Identifying outliers and influential observations in econometric models. In: Maddala, G. S., Rao, C. R. and Vinod, H. D. eds. Handbook of Statistics. Amsterdam: Elsevier, 663-701.

Duflo, E. 2005. Gender equality in development. BREAD Policy Paper 001.

Easterly, W. and Levine, R. 1997. Africa's growth tragedy: Policies and ethnic divisions. Quarterly Journal of Economics, 112(4), 1203-1250.

Elgin, S. H., 1985. A first dictionary and grammar of Laadan. Madison, WI: Society for the Furtherance and Study of Fantasy and Science Fiction. 
Feldmann, H. 2007. Protestantism, labor force participation, and employment across countries. American Journal of Economics and Sociology, 66(4), 795-816.

Fernández, R., 2008. Culture and economics. In: Durlauf, S. N. and Blume, L. E. eds. The New Palgrave Dictionary of Economics, Second Edition. Palgrave Macmillan. The New Palgrave Dictionary of Economics Online. Palgrave Macmillan. 15 April 2014 <http://www.dictionaryofeconomics.com/article?id=pde2008_E000282> doi:10.1057/9780230226203.0346

Fernández, R. and Fogli, A. 2009. Culture: An empirical investigation of beliefs, work, and fertility. American Economic Journal: Macroeconomics, 1(1), 146177.

Fortin, N. M. 2005. Gender role attitudes and labour-market outcomes of women across OECD countries. Oxford Review of Economic Policy, 21(3), 416-438.

Frye, M., 1983. The politics of reality: Essays in feminist theory. Trumansburg, NY: Crossing Press.

Gallup, J. L., Sachs, J. D. and Mellinger, A. D. 1999. Geography and economic development. International Regional Science Review, 22(2), 179-232.

Greenberg, J., 1963. Some universals of grammar with particular reference to the order of meaningful elements. In: Greenberg, J. ed. Universals of human language Cambridge: MIT Press.

Guiora, A.Z., Beit-Hallahmi, B., Fried, R. and Yoder, C. 1982. Language environment and gender identity attainment. Language Learning, 32(2), 289304. 
Hall, R. E. and Jones, C. I. 1999. Why do some countries produce so much more output per worker than others? Quarterly Journal of Economics, 114(1), 83116.

Heineck, G. 2004. Does religion influence the labor supply of married women in Germany? Journal of Socio-Economics, 33(3), 307-328.

Heston, A., Summers, R. and Aten, B. 2006. Penn World Table, Version 6.2. Center for International Comparisons of Production, Income and Prices, University of Pennsylvania.

La Porta, R., Lopez-de-Silanes, F., Shleifer, A. and Vishny, R. 1998. Law and finance. Journal of Political Economy, 106(6), 1113-1155.

Licht, A. N., Goldschmidt, C. and Schwartz, S. H. 2007. Culture rules: The foundations of the rule of law and other norms of governance. Journal of Comparative Economics, 35(4), 659-688.

Luraghi, S., 2009. The origin of the feminine gender in PIE: An old problem in a new perspective. In: Bubenik, V., Hewson, J. and Rose, S. eds. Grammatical change in Indo-European languages. Amsterdam: John Benjamins Publishing Company.

MacKinnon, C. A., 1989. Toward a feminist theory of the state. Cambridge, MA: Harvard University Press.

Masters, W. A. and McMillan, M. S. 2001. Climate and scale in economic growth. Journal of Economic Growth, 6(3), 167-186.

Miles, K. 2011. Feminist language planning in Sweden. Current Issues in Language Planning, 12(1), 21-33.

Ogunnaike, O., Dunham, Y. and Banaji, M. R. 2010. The language of implicit preferences. Journal of Experimental Social Psychology, 46(6), 999-1003. 
Pollert, A. 2003. Women, work and equal opportunities in post-Communist transition. Work, employment and society, 17(2), 331-357.

Marshall, M.G. and Jaggers, K. 2009. Polity IV project, political regime characteristics and transitions, 1800-2007, dataset users' manual: http://www.systemicpeace.org/polity.

Rodrik, D., Subramanian, A. and Trebbi, F. 2004. Institutions rule: The primacy of institutions over geography and integration in economic development. Journal of Economic Growth, 9(2), 131-165.

Rose, A. K. and Spiegel, M. M. 2009. Noneconomic engagement and international exchange: The case of environmental treaties. Journal of Money, Credit and Banking, 41(2-3), 337-363.

Ross, M. L. 2008. Oil, Islam, and women. American Political Science Review, 102(01), 107-123.

Saul, J., 2010. Feminist philosophy of language. In: Zalta, E. N. ed. The Stanford Encyclopedia of Philosophy: http://plato.stanford.edu/archives/fall2010/entries/feminism-language.

Sen, A. 1990. More than 100 million women are missing. The New York Review of Books, 37(20).

Siewierska, A., 2008. Gender distinctions in independent personal pronouns. In: Haspelmath, M., et al. eds. The World Atlas of Language Structures Online. Munich: Max Planck Digital Library: Chapter 44. http://wals.info/chapter/44.

Spender, D., 1985. Man made language. 2nd ed. New York: Routledge.

UNDP, 2010. The real wealth of nations:Pathways to human development. New York, NY.

UNESCO. 2007. Institute for Statistics, Data Centre: http://www.uis.unesco.org/. 
United Nations. 2007. Common Database: http://unstats.un.org/unsd/cdb/default.asp. von Humboldt, W., 1836. Über die Verschiedenheit des menschlichen Sprachbaues und ihren Einfluss auf die geistige Entwickelung des Menshengeschlechts. Berlin: F. Dümmler.

von Humboldt, W., 1999. On language: On the diversity of human language construction and its influence on the mental development of the human species. Cambridge, UK: Cambridge University Press.

Whorf, B. L., 1957. Language, thought and reality: Selected writings of Benjamin Lee Whorf. Cambridge: MIT Press.

World Bank, 2004. World Development Indicators 2004 CD-ROM. 
Table 1. Data on language gender and female share of labour force across countries

\begin{tabular}{|c|c|c|c|c|c|c|c|}
\hline Country & Majority lang & Lang gender & Female share of LF & Country & Majority lang & Lang gender & Female share of LF \\
\hline Argentina & Spanish & 2 & 33.3 & Madagascar & Malagasy & 0 & 44.5 \\
\hline Armenia & Armenian & 0 & 49.0 & Malawi & Chichewa & 0 & 49.0 \\
\hline Austria & German & 1 & 41.4 & Mali & Bambara & 0 & 46.1 \\
\hline Azerbaijan & Azerbaijani & 0 & 44.6 & Mauritania & Arabic & 2 & 43.9 \\
\hline Bahrain & Arabic & 2 & 21.7 & Mexico & Spanish & 2 & 33.8 \\
\hline Belgium & Dutch & 1 & 41.0 & Nepal & Nepali & 0 & 39.4 \\
\hline Bolivia & Spanish & 2 & 37.8 & Netherlands & Dutch & 1 & 40.7 \\
\hline Brazil & Portuguese & 1 & 35.5 & New Zealand & English & 1 & 45.8 \\
\hline Bulgaria & Bulgarian & 1 & 48.0 & Nicaragua & Spanish & 2 & 36.2 \\
\hline
\end{tabular}




\begin{tabular}{|c|c|c|c|c|c|c|c|}
\hline Cambodia & Khmer & 0 & 52.3 & Niger & Hausa & 2 & 43.2 \\
\hline Canada & English & 1 & 45.9 & Nigeria & Yoruba & 0 & 36.3 \\
\hline Chile & Spanish & 2 & 33.6 & Norway & Norwegian & 1 & 46.6 \\
\hline China & Mandarin & 1 & 45.1 & Oman & Arabic & 2 & 17.2 \\
\hline Colombia & Spanish & 2 & 39.1 & Pakistan & Punjabi & 0 & 28.9 \\
\hline Congo & Kongo & 1 & 43.1 & Panama & Spanish & 2 & 35.3 \\
\hline Costa Rica & Spanish & 2 & 31.5 & Philippines & Tagalog & 0 & 37.9 \\
\hline Croatia & Croatian & 1 & 44.4 & Poland & Polish & 1 & 46.4 \\
\hline Cuba & Spanish & 2 & 39.6 & Portugal & Portuguese & 1 & 44.0 \\
\hline Czech Rep & Czech & 1 & 47.2 & Rep of Korea & Korean & 1 & 41.4 \\
\hline Denmark & Danish & 1 & 46.7 & Rep of Moldova & Romanian & 1 & 48.9 \\
\hline Dominican Rep & Spanish & 2 & 30.8 & Romania & Romanian & 1 & 44.7 \\
\hline Ecuador & Spanish & 2 & 28.0 & Russian Fed & Russian & 1 & 49.2 \\
\hline Egypt & Arabic & 2 & 30.5 & Saudi Arabia & Arabic & 2 & 17.7 \\
\hline El Salvador & Spanish & 2 & 36.3 & Senegal & Wolof & 0 & 43.2 \\
\hline Eritrea & Tigrinya & 2 & 47.4 & Slovakia & Slovak & 1 & 47.8 \\
\hline
\end{tabular}




\begin{tabular}{|c|c|c|c|c|c|c|c|}
\hline Estonia & Estonian & 0 & 49.5 & Slovenia & Slovene & 1 & 46.4 \\
\hline Ethiopia & Oromo & 1 & 41.4 & South Africa & Zulu & 1 & 38.5 \\
\hline Finland & Finnish & 0 & 48.1 & Spain & Spanish & 2 & 37.4 \\
\hline France & French & 1 & 45.3 & Sri Lanka & Sinhala & 1 & 35.5 \\
\hline Georgia & Georgian & 0 & 46.8 & Sudan & Arabic & 2 & 29.5 \\
\hline Greece & Greek & 1 & 37.8 & Sweden & Swedish & 1 & 48.0 \\
\hline Guatemala & Spanish & 2 & 29.1 & Switzerland & German & 1 & 40.4 \\
\hline Guinea & Fula & 0 & 47.2 & Syria & Arabic & 2 & 26.9 \\
\hline Guyana & English & 1 & 35.2 & Tajikistan & Tajik & 0 & 44.9 \\
\hline Honduras & Spanish & 2 & 31.9 & Thailand & Thai & 0 & 47.1 \\
\hline Hungary & Hungarian & 0 & 44.5 & FYR Macedonia & Macedonian & 1 & 42.2 \\
\hline India & Hindi & 0 & 32.3 & Togo & Ewe & 0 & 40.0 \\
\hline Iran & Persian & 0 & 27.0 & Tunisia & Arabic & 2 & 31.9 \\
\hline Ireland & English & 1 & 35.0 & Turkey & Turkish & 0 & 38.2 \\
\hline Israel & Hebrew & 2 & 41.4 & Turkmenistan & Turkmen & 0 & 46.0 \\
\hline Italy & Italian & 1 & 38.6 & Ukraine & Ukrainian & 1 & 48.9 \\
\hline
\end{tabular}




\begin{tabular}{|c|c|c|c|c|c|c|c|}
\hline Jamaica & English & 1 & 47.5 & United Kingdom & English & 1 & 43.8 \\
\hline Japan & Japanese & 1 & 41.5 & United States & English & 1 & 46.4 \\
\hline Jordan & Arabic & 2 & 23.9 & Uruguay & Spanish & 2 & 42.0 \\
\hline Kazakhstan & Kazakh & 0 & 47.3 & Uzbekistan & Uzbek & 0 & 46.9 \\
\hline Kuwait & Arabic & 2 & 21.5 & Venezuela & Spanish & 2 & 34.8 \\
\hline Kyrgyzstan & Kyrgyz & 0 & 47.4 & Viet Nam & Vietnamese & 0 & 48.7 \\
\hline Laos & Lao & 0 & 46.7 & Yemen & Arabic & 2 & 28.6 \\
\hline Latvia & Latvian & 1 & 49.7 & Zimbabwe & Shona & 0 & 44.2 \\
\hline
\end{tabular}

Notes: 'Lang gender' is the gender intensity defined with respect to the language spoken as 'mother tongue' by the majority population. 0 denotes gender-neutral languages; 1 mildly gendered and 2 highly gendered languages. 'Female share of LF' is the female share of the native non-agricultural labour force. 
Table 2. Country level descriptive statistics

\begin{tabular}{|c|c|c|c|c|c|}
\hline Variable & Sources & Mean & Std. dev. & Min & Max \\
\hline Female share of LF & Ross (2008) & 40.11 & 7.86 & 17.21 & 52.33 \\
\hline Highly gendered & Siewierska (2008) & 0.31 & 0.47 & 0 & 1 \\
\hline Mildly gendered & Siewierska (2008) & 0.39 & 0.49 & 0 & 1 \\
\hline Ling major sh & Alesina et al. (2003) & 77.26 & 21.33 & 21.35 & 100 \\
\hline Ln income & Heston et al. (2006) & 8.67 & 1.08 & 6.24 & 10.44 \\
\hline Gov size & Heston et al. (2006) & 22.30 & 10.24 & 3.79 & 71.05 \\
\hline Openness & Rose and Spiegel (2009) & 83.85 & 40.36 & 20.18 & 228.88 \\
\hline Oil rents & Ross (2008) & 361.73 & 1182.33 & 0 & 9960.77 \\
\hline Democracy & Rose and Spiegel (2009) & 5.87 & 3.89 & 0 & 10 \\
\hline Ln population & Heston et al. (2006) & 16.42 & 1.41 & 13.36 & 20.96 \\
\hline \multirow[t]{2}{*}{ Urban sh } & UNESCO (2007); & 57.31 & 21.29 & 13.70 & 97.10 \\
\hline & \multicolumn{5}{|l|}{ United Nations (2007) } \\
\hline Protestant sh & Barro (2007) & 9.30 & 17.79 & 0 & 89.70 \\
\hline Catholic sh & Barro (2007) & 27.92 & 34.96 & 0 & 94.30 \\
\hline Muslim sh & Barro (2007) & 26.35 & 37.20 & 0 & 99.10 \\
\hline Jewish sh & Barro (2007) & 0.87 & 7.41 & 0 & 77.10 \\
\hline Hindu sh & Barro (2007) & 2.29 & 10.92 & 0 & 77.10 \\
\hline Buddhist sh & Barro (2007) & 4.35 & 15.61 & 0 & 85.30 \\
\hline Communist & Barro (2007) & 0.31 & 0.47 & 0 & 1 \\
\hline \multicolumn{6}{|c|}{$\begin{array}{l}\text { Notes: The list of countries in the sample is provided in Table 1. 'Sources' lists the sources of raw } \\
\text { data based on which the dataset used in this paper was assembled. 'Female share of LF' is the female } \\
\text { share of the native non-agricultural labour force. 'Highly gendered' and 'Mildly gendered' are } \\
\text { dummies for gender intensity defined with respect to the language spoken as 'mother tongue' by the }\end{array}$} \\
\hline
\end{tabular}


Table 3. Country level estimates on different samples
(1)
(2)
(3)
(4)
(5)
(6)

Dependent variable: Female share of LF

\begin{tabular}{|c|c|c|c|c|c|c|}
\hline \multirow[t]{2}{*}{ Highly gendered } & $-4.386 * * *$ & $-4.2659 * *$ & $-4.5593 * * *$ & $-5.1323 * *$ & $-2.8991 *$ & $-3.2504 * *$ \\
\hline & $(1.6687)$ & $(2.0244)$ & (1.6815) & $(2.0292)$ & $(1.5144)$ & $(1.5847)$ \\
\hline \multirow[t]{2}{*}{ Mildly gendered } & $-2.324^{*}$ & $-2.4711 * *$ & $-3.1219 * *$ & $-3.9085^{* *}$ & $-2.1724 * *$ & $-1.7916^{*}$ \\
\hline & $(1.2088)$ & $(1.2023)$ & $(1.4077)$ & (1.8194) & $(1.0472)$ & $(1.0702)$ \\
\hline \multirow[t]{2}{*}{ Ling major sh } & $0.0447 *$ & $0.0475 *$ & $0.0518 * *$ & $0.0561 * *$ & $0.0446 * *$ & $0.0361 *$ \\
\hline & $(0.024)$ & $(0.0242)$ & $(0.0247)$ & $(0.0278)$ & $(0.0209)$ & $(0.0212)$ \\
\hline \multirow[t]{2}{*}{ Ln income } & -7.2374 & -11.7376 & -7.0285 & -5.7639 & -7.9186 & -0.3432 \\
\hline & $(9.1217)$ & $(8.8955)$ & $(9.2059)$ & $(10.8771)$ & $(7.8876)$ & $(9.5193)$ \\
\hline \multirow[t]{2}{*}{ Ln income sq } & 0.4018 & 0.6769 & 0.4043 & 0.3171 & 0.4438 & -0.0393 \\
\hline & $(0.5495)$ & $(0.5383)$ & $(0.5545)$ & $(0.6446)$ & $(0.4752)$ & $(0.5706)$ \\
\hline \multirow[t]{2}{*}{ Gov size } & 0.0064 & 0.0321 & 0.0132 & 0.0282 & -0.0179 & -0.0549 \\
\hline & $(0.0478)$ & $(0.0522)$ & $(0.0484)$ & $(0.0563)$ & $(0.0414)$ & $(0.0474)$ \\
\hline \multirow[t]{2}{*}{ Openness } & -0.0056 & -0.009 & -0.0017 & -0.0048 & -0.0107 & -0.0079 \\
\hline & $(0.0122)$ & $(0.0116)$ & $(0.0127)$ & $(0.015)$ & $(0.0104)$ & $(0.011)$ \\
\hline \multirow[t]{2}{*}{ Oil rents } & $-0.001 * *$ & 0.0002 & $-0.0011 * *$ & $-0.001 * *$ & $-0.002 * * *$ & $-0.0018 * * *$ \\
\hline & $(0.0005)$ & $(0.0011)$ & $(0.0005)$ & $(0.0005)$ & $(0.0006)$ & $(0.0006)$ \\
\hline \multirow[t]{2}{*}{ Democracy } & 0.2846 & 0.2293 & $0.321 *$ & 0.3724 & 0.1573 & 0.131 \\
\hline & $(0.1801)$ & $(0.1815)$ & $(0.1827)$ & $(0.2314)$ & $(0.1604)$ & $(0.1565)$ \\
\hline \multirow[t]{2}{*}{ Ln population } & -0.0704 & -0.2894 & 0.0275 & -0.1185 & -0.0512 & 0.0867 \\
\hline & $(0.3775)$ & $(0.3759)$ & $(0.3856)$ & $(0.4575)$ & $(0.3236)$ & $(0.3427)$ \\
\hline \multirow[t]{2}{*}{ Urban sh } & 0.0188 & 0.0344 & 0.0153 & 0.0277 & 0.0278 & 0.0277 \\
\hline & $(0.0369)$ & $(0.0389)$ & $(0.0375)$ & $(0.0429)$ & $(0.0317)$ & $(0.0335)$ \\
\hline Protestant sh & 0.0102 & -0.0057 & 0.0219 & 0.0065 & 0.0125 & 0.0493 \\
\hline
\end{tabular}




\begin{tabular}{|c|c|c|c|c|c|c|}
\hline & $(0.0326)$ & $(0.0328)$ & $(0.0354)$ & $(0.0367)$ & $(0.0307)$ & $(0.031)$ \\
\hline \multirow[t]{2}{*}{ Catholic sh } & $-0.0524 * *$ & $-0.0519 * * *$ & $-0.0495 * *$ & $-0.0569 * *$ & $-0.05 * * *$ & -0.0302 \\
\hline & $(0.0204)$ & $(0.019)$ & $(0.0209)$ & $(0.0234)$ & $(0.019)$ & $(0.0193)$ \\
\hline \multirow[t]{2}{*}{ Muslim sh } & -0.0242 & -0.0332 & -0.0258 & -0.0279 & -0.01 & -0.0011 \\
\hline & $(0.0227)$ & $(0.0227)$ & $(0.0233)$ & $(0.0287)$ & $(0.0202)$ & $(0.0206)$ \\
\hline \multirow[t]{2}{*}{ Jewish sh } & $0.1275^{* *}$ & 0.0952 & $0.121^{*}$ & 0.1164 & $0.1471 * * *$ & $2.2441 *$ \\
\hline & $(0.0613)$ & $(0.0668)$ & $(0.0625)$ & $(0.0704)$ & $(0.0521)$ & (1.1724) \\
\hline \multirow[t]{2}{*}{ Hindu sh } & -0.0721 & -0.0666 & -0.0708 & -0.0792 & $-0.0701 *$ & -0.0218 \\
\hline & $(0.0467)$ & $(0.0461)$ & $(0.0471)$ & $(0.0517)$ & $(0.0413)$ & $(0.1227)$ \\
\hline \multirow[t]{2}{*}{ Buddhist sh } & 0.0483 & 0.0449 & 0.0481 & 0.0342 & 0.038 & 0.0674 \\
\hline & $(0.0395)$ & $(0.0379)$ & (0.0399) & $(0.0511)$ & $(0.0347)$ & $(0.0474)$ \\
\hline \multirow[t]{2}{*}{ Communist } & $4.5345 * * *$ & $3.7585 * *$ & $4.8114 * * *$ & $4.7505^{* *}$ & $4.0994 * * *$ & $3.6608 * *$ \\
\hline & $(1.7203)$ & $(1.6829)$ & (1.7398) & $(2.0322)$ & $(1.4682)$ & $(1.4538)$ \\
\hline \multirow[t]{2}{*}{ Constant } & $73.4557 *$ & $94.8962 * *$ & $69.1913 *$ & 67.2725 & $77.4486 * *$ & 46.5481 \\
\hline & $(39.9276)$ & (39.1604) & (40.3794) & $(47.9862)$ & $(34.3566)$ & $(40.9463)$ \\
\hline Region effects & Yes & Yes & Yes & Yes & Yes & Yes \\
\hline No of obs & 108 & 94 & 105 & 94 & 102 & 94 \\
\hline R-sq & 0.8219 & 0.7438 & 0.8219 & 0.8082 & 0.8695 & 0.8937 \\
\hline
\end{tabular}

Notes: Estimated coefficients are based on OLS regressions. Standard errors are in parenthesis. ${ }^{*}$ denotes significance at 10 percent level; ** at 5 percent level; *** at 1 percent level. 'Female share of LF' is the female share of the native non-agricultural labour force. 'Highly gendered' and 'Mildly gendered' are dummies for gender intensity defined with respect to the language spoken as 'mother tongue' by the majority population. (1) is based on the full sample; (2) excludes Arabic-speaking countries; (3) excludes Estonia, Finland and Hungary; (4) excludes former Communist countries speaking gender-neutral languages; (5) removes influential observations based on studentised residuals; and (6) removes influential observations based on Cook's distance. 
Table 4. Country level robustness checks: Alternative measurement of variables

$$
\text { (1) }
$$

(3)

(4)

(5)

Dependent variable:

\begin{tabular}{llllll}
\hline & \multicolumn{1}{l}{ Female share of } & Ratio of female & Female & Female & Female share \\
& LF - unadjusted & to male LFPR & LFPR & employment rate & of LF \\
\hline Highly gendered & $-7.2475^{* * *}$ & $-17.7722^{* * *}$ & $-14.1247^{* * *}$ & $-14.9415^{* * *}$ & $-0.0637^{* *}$ \\
& $(1.8887)$ & $(4.2092)$ & $(4.1390)$ & $(4.1155)$ & $(0.0247)$ \\
Mildly gendered & $-3.3446^{* *}$ & $-6.8344^{* *}$ & $-6.4896^{* *}$ & $-8.0311^{* * *}$ & -0.0177 \\
& $(1.3379)$ & $(2.9816)$ & $(2.9319)$ & $(2.9814)$ & $(0.0159)$ \\
Other controls & Yes & Yes & Yes & Yes & Yes \\
\hline No of obs & 109 & 109 & 109 & 108 & 85 \\
R-sq & 0.8449 & 0.8224 & 0.7737 & 0.7238 & 0.8322
\end{tabular}

Notes: Estimated coefficients are based on OLS regressions. Standard errors are in parenthesis. * denotes significance at 10 percent level; $* *$ at 5 percent level; *** at 1 percent level. 'Female share of LF - unadjusted' is the female share of the total labour force (including foreign and agricultural workers). 'Ratio of female to male LFPR' is the ratio of female to male labour force participation rates. 'Female LFPR' is the economically active share of the working-age female population. 'Female employment rate' is the proportion of working-age female population who are employed. 'Female share of LF' is the female share of the native non-agricultural labour force. 'Highly gendered' and 'Mildly gendered' are dummies for gender intensity defined with respect to the language spoken as 'mother tongue' by the majority population, with the exception of column (5) where they are defined as continuous variables which are the population shares speaking highly and mildly gendered languages. The baseline control set used is identical to Table 3, with the addition of the population share speaking languages with unknown gender characteristics in column (5). 
Table 5. Country level robustness checks: Addressing unobserved heterogeneity

Dependent variable: Female share of LF

$\begin{array}{lllllll}\text { Highly gendered } & -4.4754 * * * & -4.7068^{* * *} & -4.8245 * * * & -4.5094 * * * & -7.7022^{* * *} & -5.0745 * * \\ \text { Mildly gendered } & (1.6779) & (1.6544) & (1.7484) & (1.6311) & (2.5372) & (2.0587) \\ & -2.3621^{*} & -2.1616^{*} & -2.4959^{*} & -2.3116^{*} & -2.7856^{*} & -2.5429 * \\ \text { Future time-ref } & (1.2134) & (1.1951) & (1.2776) & (1.194) & (1.5326) & (1.4505) \\ & 0.8312 & & & & & \\ & (1.1439) & & & & & \end{array}$

Dist from equator

$8.6254^{*}$

(4.6743)

Tropical pop sh

0.0022

(0.0188)

Avg num frost days

0.1148

(0.0982)

Pop sh 100 km coast

$0.037 * *$

(0.0181) 
Landlocked

1.7039

(1.2609)

British colony

$-0.4885$

(1.5336)

French colony

$3.3704 * *$

(1.5279)

English common law

$-0.2748$

(2.1252)

French civil law

0.0354

(2.0871)

Unemployment benefits

Maximum advance notice

Maximum severance payment

Other controls
Yes

Yes
3.6689

(4.2182)

$-0.1871$

$(0.1961)$

0.1210

(0.0786)

-




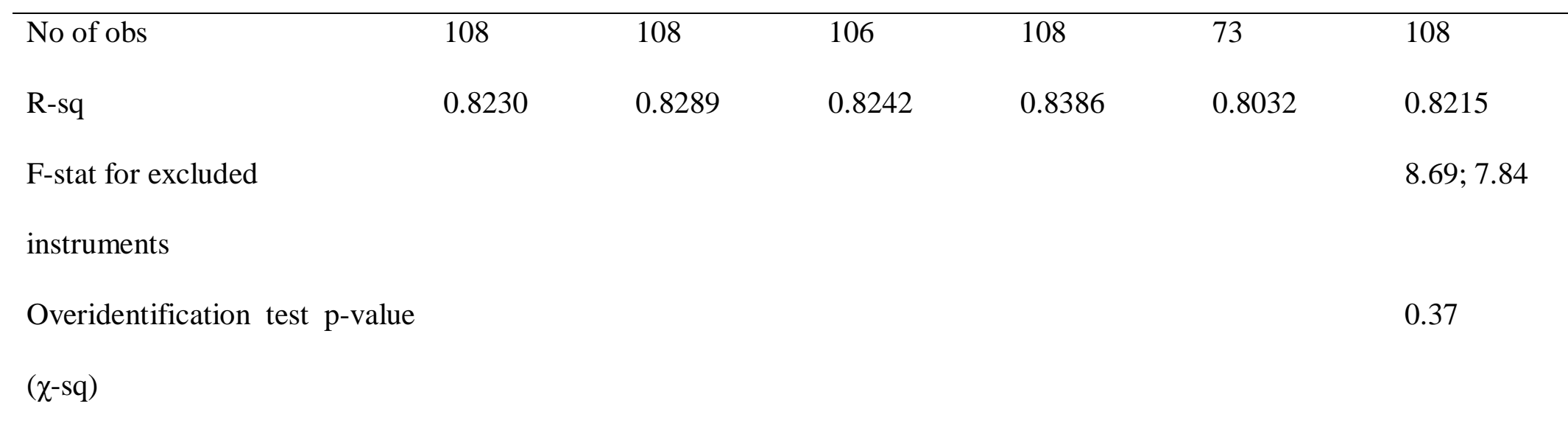

Notes: Estimated coefficients are based on OLS regressions with the exception of column (6) where $2^{\text {nd }}$ stage coefficients from 2 SLS regression are reported. Standard errors are in parenthesis. * denotes significance at 10 percent level; ** at 5 percent level; *** at 1 percent level. 'Female share of LF' is the female share of the native non-agricultural labour force. 'Highly gendered' and 'Mildly gendered' are dummies for gender intensity defined with respect to the language spoken as 'mother tongue' by the majority population. The baseline control set used is identical to Table 3. 
Table 6. Individual level estimates
(1)
(2)
(3)
(4)
(5)

Dependent variable:

\begin{tabular}{|c|c|c|c|c|c|}
\hline & \multicolumn{2}{|l|}{ Employment } & \multicolumn{2}{|c|}{ Part-time employment } & \multirow{2}{*}{$\begin{array}{l}\text { Discrim attitudes } \\
\text { All }\end{array}$} \\
\hline & Women & Men & Women & Men & \\
\hline \multirow[t]{2}{*}{ Highly gendered } & -0.1845 & 0.0158 & 0.0468 & -0.0118 & $0.1245 * * *$ \\
\hline & $(0.1410)$ & $(0.0186)$ & $(0.0794)$ & $(0.0143)$ & $(0.0460)$ \\
\hline \multirow[t]{2}{*}{ Mildly gendered } & $-0.1169 *$ & 0.0160 & $0.0851 * *$ & 0.0311 & $0.1003 * * *$ \\
\hline & $(0.0674)$ & $(0.0158)$ & $(0.0401)$ & $(0.0201)$ & $(0.0331)$ \\
\hline \multirow[t]{2}{*}{ Woman } & & & & & $-0.1448 * * *$ \\
\hline & & & & & $(0.0158)$ \\
\hline \multirow[t]{2}{*}{ Interview lang same } & 0.0618 & 0.0197 & -0.0275 & 0.0030 & $-0.0669 * * *$ \\
\hline & $(0.0484)$ & $(0.0226)$ & $(0.0375)$ & $(0.0097)$ & $(0.0244)$ \\
\hline \multirow[t]{2}{*}{ Interview lang less gender } & 0.1218 & 0.0270 & -0.0376 & 0.0481 & $-0.1043 * *$ \\
\hline & $(0.0843)$ & $(0.0245)$ & $(0.0734)$ & $(0.0313)$ & $(0.0483)$ \\
\hline \multirow[t]{2}{*}{ Protestant } & 0.0094 & 0.0097 & $0.0304 *$ & -0.0043 & $0.0309 *$ \\
\hline & $(0.0366)$ & $(0.0123)$ & $(0.0174)$ & $(0.0139)$ & $(0.0186)$ \\
\hline \multirow[t]{2}{*}{ Catholic } & -0.0038 & -0.0088 & 0.0213 & -0.0066 & 0.0073 \\
\hline & $(0.0259)$ & $(0.098)$ & $(0.0141)$ & $(0.0111)$ & $(0.0168)$ \\
\hline \multirow[t]{2}{*}{ Muslim } & $-0.1207 * * *$ & -0.0099 & $0.0603^{*}$ & 0.0205 & $0.0888 * * *$ \\
\hline & $(0.0371)$ & $(0.0114)$ & $(0.0310)$ & $(0.0164)$ & $(0.0212)$ \\
\hline \multirow[t]{2}{*}{ Jewish } & -0.0395 & -0.0405 & -0.0100 & 0.0164 & -0.0223 \\
\hline & $(0.0797)$ & $(0.0378)$ & $(0.0421)$ & $(0.0399)$ & $(0.0598)$ \\
\hline \multirow[t]{2}{*}{ Hindu } & $-0.1393 * * *$ & 0.0036 & -0.0363 & -0.0088 & $0.1183 * *$ \\
\hline & $(0.0461)$ & $(0.0167)$ & $(0.0271)$ & $(0.0172)$ & $(0.0548)$ \\
\hline
\end{tabular}




\begin{tabular}{|c|c|c|c|c|c|}
\hline \multirow[t]{2}{*}{ Buddhist } & 0.0291 & -0.0409 & -0.0388 & 0.0101 & -0.0131 \\
\hline & $(0.0301)$ & $(0.0291)$ & $(0.0304)$ & $(0.0282)$ & $(0.0208)$ \\
\hline \multirow[t]{2}{*}{ Other denomination } & $0.0466^{*}$ & 0.0145 & 0.0165 & -0.0125 & -0.0098 \\
\hline & $(0.0239)$ & $(0.0099)$ & $(0.0242)$ & $(0.0111)$ & $(0.0184)$ \\
\hline \multirow[t]{2}{*}{ Frequent relig attend } & $-0.0504 * * *$ & $0.0111 *$ & $0.0345^{*}$ & $0.0183^{*}$ & $0.0629 * * *$ \\
\hline & $(0.0156)$ & $(0.0066)$ & $(0.0188)$ & $(0.0096)$ & $(0.0185)$ \\
\hline \multirow[t]{2}{*}{ Weekly relig attend } & $-0.0337 * *$ & 0.0095 & $0.0286^{*}$ & 0.0040 & $0.0595 * * *$ \\
\hline & $(0.0146)$ & $(0.0068)$ & $(0.0153)$ & $(0.0064)$ & $(0.0127)$ \\
\hline \multirow[t]{2}{*}{ Monthly relig attend } & -0.0112 & 0.0085 & $0.0409 * * *$ & 0.0044 & 0.0169 \\
\hline & $(0.0142)$ & $(0.0092)$ & $(0.0110)$ & $(0.0081)$ & $(0.0108)$ \\
\hline \multirow[t]{2}{*}{ Religious } & -0.0126 & -0.0053 & -0.0092 & -0.0008 & $0.0425^{* * *}$ \\
\hline & $(0.0125)$ & $(0.0047)$ & $(0.0103)$ & $(0.0057)$ & $(0.0152)$ \\
\hline \multirow[t]{2}{*}{ Age } & $0.0029 * * *$ & $0.0011 * *$ & $-0.0011 * *$ & $-0.0008 * * *$ & $0.0016^{* * *}$ \\
\hline & $(0.0011)$ & $(0.0005)$ & $(0.0004)$ & $(0.0003)$ & $(0.0005)$ \\
\hline \multirow[t]{2}{*}{ Married } & $-0.0945 * * *$ & $0.1445 * * *$ & -0.0244 & $-0.0571 * * *$ & $0.0326^{* *}$ \\
\hline & $(0.0301)$ & $(0.0145)$ & $(0.0166)$ & $(0.0096)$ & $(0.0133)$ \\
\hline \multirow[t]{2}{*}{ Divorced } & $0.0691 * *$ & $0.0456^{* * *}$ & $-0.0619 * * *$ & $-0.0249 * * *$ & -0.0129 \\
\hline & $(0.0274)$ & $(0.0075)$ & $(0.0191)$ & $(0.0097)$ & $(0.0153)$ \\
\hline \multirow[t]{2}{*}{ No. of children } & $-0.0241 * * *$ & -0.0022 & 0.0089 & -0.0008 & $0.0061 * *$ \\
\hline & $(0.0052)$ & $(0.0019)$ & $(0.0063)$ & $(0.0028)$ & $(0.0027)$ \\
\hline \multirow[t]{2}{*}{ White race } & -0.0311 & 0.0034 & -0.0191 & -0.0063 & 0.0123 \\
\hline & $(0.0406)$ & $(0.0115)$ & $(0.0220)$ & $(0.0080)$ & $(0.0241)$ \\
\hline \multirow[t]{2}{*}{ Good health } & 0.0085 & $0.0181 * * *$ & -0.0056 & -0.0002 & -0.0116 \\
\hline & $(0.0121)$ & $(0.0066)$ & $(0.0131)$ & $(0.0062)$ & $(0.0086)$ \\
\hline Poor health & $-0.0960 * * *$ & $-0.0395 * *$ & -0.0075 & $0.0232 * *$ & 0.0017 \\
\hline
\end{tabular}




\begin{tabular}{|c|c|c|c|c|c|}
\hline & $(0.0216)$ & $(0.0157)$ & $(0.0302)$ & $(0.0107)$ & $(0.0194)$ \\
\hline \multirow[t]{2}{*}{ Educ inadequate } & $-0.3648 * * *$ & $-0.0893 * * *$ & -0.0225 & 0.0073 & $0.2204 * * *$ \\
\hline & $(0.0325)$ & $(0.0241)$ & $(0.0316)$ & $(0.0158)$ & $(0.0194)$ \\
\hline \multirow[t]{2}{*}{ Educ lower } & $-0.3298 * * *$ & $-0.0626 * * *$ & -0.0229 & -0.0110 & $0.1760 * * *$ \\
\hline & $(0.0268)$ & $(0.0141)$ & $(0.0202)$ & $(0.0109)$ & $(0.0131)$ \\
\hline \multirow[t]{2}{*}{ Educ middle } & $-0.2191 * * *$ & $-0.0509 * * *$ & $-0.0241 *$ & $-0.0151 * *$ & $0.1036 * * *$ \\
\hline & $(0.0241)$ & $(0.0081)$ & $(0.0124)$ & $(0.0075)$ & $(0.0104)$ \\
\hline Income dummies & Yes & Yes & Yes & Yes & Yes \\
\hline Town size dummies & Yes & Yes & Yes & Yes & Yes \\
\hline Country dummies & Yes & Yes & Yes & Yes & Yes \\
\hline Region dummies & Yes & Yes & Yes & Yes & Yes \\
\hline Year dummies & Yes & Yes & Yes & Yes & Yes \\
\hline No. of obs & 20,673 & 18,833 & 10,310 & 16,331 & 39,738 \\
\hline No. of countries & 45 & 46 & 44 & 45 & 46 \\
\hline Pseudo R-sq & 0.23 & 0.17 & 0.08 & 0.07 & 0.28 \\
\hline Log pseudo-likelihood & -10993.83 & -6129.03 & -4758.17 & -4798.40 & -19701.04 \\
\hline
\end{tabular}

Notes: Marginal effects of probit regressions calculated at the means are reported; Standard errors clustered at the country level are in parenthesis; $*$ denotes significance at 10 percent level, ** at 5 percent level, $* * *$ at 1 percent level. 'Employment' equals 1 for those employed full-time or parttime or self-employed, and 0 for housewives or unemployed. 'Part-time employment' equals 1 for those employed part-time and 0 for those employed full-time or who are self-employed. 'Discrim attitudes' equals 1 for agreement on: 'When jobs are scarce men should have ore right to a job than women' and 0 for disagreement. 'Highly gendered' and 'Mildly gendered' are dummies for genderintensity defined with respect to the language spoken at home. Interview lang variables refer to the language in which answers were elicited during the interview and measure whether and the extent to 
which it is different from the language spoken at home. Excluded dummies are: Gender-neutral lang; Male; Interview lang more gender intensive (relative to the language spoken at home); No religious denomination; Occasional or no attendance to religious services; Not-religious (self-reported); Single; Other races; Fair health; University education. 